\title{
Cerebral White Matter Hyperintensities on MRI: Current Concepts and Therapeutic Implications
}

\author{
Bruce Ovbiagele Jeffrey L. Saver \\ Stroke Center and Department of Neurology, University of California at Los Angeles Medical Center, \\ Los Angeles, Calif., USA
}

\section{Key Words}

Cerebral white matter hyperintensities - Covert

vascular brain injury $\cdot$ Stroke

\begin{abstract}
Background: White matter hyperintensities (WMH) are commonly observed MRI abnormalities in the elderly, which generally reflect covert vascular brain injury. WMH cumulatively produce substantial neurologic, psychiatric, and medical morbidity. This review provides an overview of current knowledge on vascular $\mathrm{WMH}$, and describes some pharmacological agents that may have a role in mitigating this condition. Summary of Review: This review has two main focus areas. The first is a discussion of currently available knowledge regarding the public health burden, pathogenesis, and various risk factors associated with the presence of vascular white matter lesions noted on brain MRI. The second section of the article details the mechanistic and clinical basis for promising pharmacological treatment modalities that could potentially prevent progression of ischemic cerebral white matter brain injury. Many of these therapies are already of proven efficacy in preventing recurrent stroke. Conclusions: Individuals with vascular white matter lesions on MRI may represent a potential target population likely to benefit from secondary stroke prevention therapies.
\end{abstract}

Copyright (C) 2006 S. Karger AG, Basel

\section{KARGER}

Fax +41613061234 E-Mail karger@karger.ch www.karger.com (c) 2006 S. Karger AG, Basel $1015-9770 / 06 / 0223-0083 \$ 23.50 / 0$

Accessible online at: www.karger.com/ced

\section{Current Concepts}

Public Health Burden of Ischemic White Matter Injuries

About 750,000 Americans experience first-ever or recurrent stroke annually $[1,2]$. However, these estimates reflect only clinically manifest, symptomatic strokes and fail to take into account the annual toll of vascular cerebral white matter injury within the American population. In the elderly, symptomatic stroke has a prevalence of 4.7\% [3], but MRI white matter hyperintensities (WMH) are found in a significant proportion of the communitydwelling elderly population and the incidence of these lesions approaches $100 \%$ by the age of $85[4,5]$. WMH may initially produce no symptoms or only mild, nonspecific and/or unrecognized symptoms, but eventually can lead to substantial neurological, psychiatric, and medical morbidity. WMH are associated with cognitive dysfunction, frank dementia, depression [6, 7], psychosis, gait impairment and falls [8-10], hand incoordination $[9,10]$, and markedly increased risk of future symptomatic stroke.

\section{MRI White Matter Hyperintensities}

$\mathrm{WMH}$ are areas of bright, high signal intensities noted on MRI $\mathrm{T}_{2}$-weighted and proton density sequences, representing regions of scattered brain white matter loss associated with local increases in brain water content. These 
Table 1. Annual increase in white matter lesion volume $\left(\mathrm{cm}^{3}\right)$ in subjects with different grades of WMH at study entry

\begin{tabular}{|c|c|c|c|c|c|}
\hline \multirow[t]{2}{*}{ Study } & \multirow[t]{2}{*}{ Subjects } & \multicolumn{4}{|c|}{ Baseline WMH grade } \\
\hline & & none & punctate & $\begin{array}{l}\text { early } \\
\text { confluent }\end{array}$ & $\begin{array}{l}\text { con- } \\
\text { fluent }\end{array}$ \\
\hline Austrian Stroke Prevention, 2003 [15] & 296 & 0 & 0.03 & 0.23 & 1.60 \\
\hline French PROGRESS MRI Study Placebo, 2005 [16] & 103 & & 0 & 0.43 & 2.53 \\
\hline
\end{tabular}

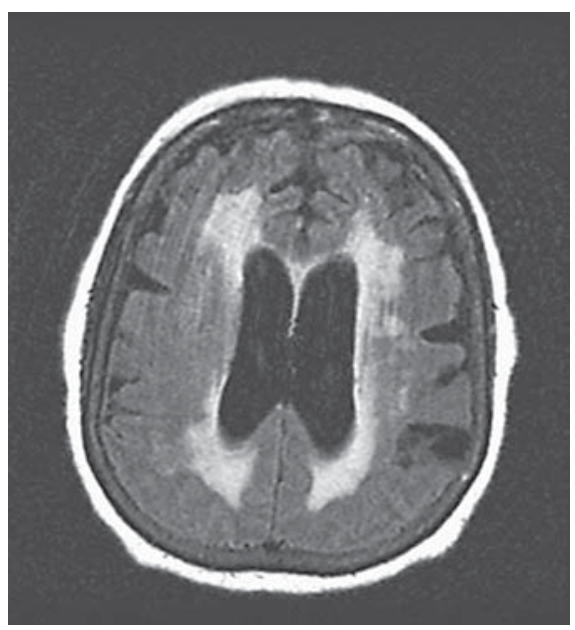

Fig. 1. $M R I T_{2}$-weighted sequences showing confluent WMH.

hyperintensities reflect leukoaraiosis (from the Greek leuko $=$ white, araios $=$ rarefied), a term coined by Hachinski et al. [11] to indicate 'a diminution of the density of representation of the white matter' on neuroimaging.

WMH of vascular origin can also be divided into punctate, early confluent and confluent hyperintensities [12, 13]. Punctate lesions tend to correspond to a perivascular reduction in myelin content with atrophy of the neuropil and seem to constitute a negligible extent of tissue damage from low permeability through thickened arteriolar walls. Early confluent and confluent (fig. 1) hyperintensities, however, indicate more extensive ischemic damage consistent with advanced microangiopathy. [12, 13].

\section{Progression of WMH and the Distinctly High Risk of}

Subjects with Confluent Lesions

The presence of confluent WMH at the time of initial observation has been shown to be a potent predictor of subsequent WMH progression [14]. Early confluent and confluent white matter abnormalities are progressive, and likely malignant. Two large population studies have provided detailed information regarding the dramatic differences in the rate of progression of lesion volume in individuals with different degrees of baseline WMH (table 1). The Austrian Stroke Prevention Study investigators performed a population-based study assessing the progression of white matter lesions in community-dwelling volunteers aged $50-75$ years without neuropsychiatric disease [15]. MRIs were obtained in 296 volunteers at baseline, 3 years and 6 years, and the total volume of white matter lesions was measured. Those participants with no lesions and with punctate abnormalities at baseline had a low tendency for lesion progression, whereas those participants with early confluent and with confluent lesions showed substantial median increases in lesion volume at 6 years. Lesion grade at baseline was found to be a significant predictor of lesion progression $(p<0.0001)$ [15].

In the PROGRESS MRI substudy, a multicenter study group in France obtained baseline and 3-year MRIs in consecutive stroke subjects enrolled in the international PROGRESS trial of poststroke antihypertensive therapy [16]. In the placebo group, lesion grade at baseline was powerfully related to lesion progression, with no progression seen in mild baseline subjects, and fivefold greater progression seen in confluent subjects compared to early confluent subjects.

\section{Pathogenesis}

Pathologic correlation has shown that these patchy white matter lesions correspond primarily to areas of ischemic demyelination and gliosis, and occasionally to clinically silent infarcts [17]. Chronic low-grade vascular insufficiency produces atrophic perivascular demyelination rather than acute tissue necrosis created by more severe ischemia. The $\mathrm{WMH}$ are presumably mostly caused by hypoperfusion and arteriolar disease [18]. Lipohyalinosis of the media and thickening of the vessel walls narrow the lumen of the small perforating arteries 
and arterioles which nourish the deep white matter [19]. The perforating vessels, which originate from cortical and leptomeningeal arteries, have a relatively poor anastomotic system, which makes the white matter vulnerable to cerebral ischemia. Postmortem studies have indicated that WMH seen on MRI scans are associated with degenerative changes in arterioles that are related to atherosclerosis, suggesting that cerebral arteriosclerosis of the penetrating vessels is a major factor in the pathogenesis of ischemic WMH [19].

\section{Risk Factors for Cerebral Ischemic White Matter Injury \\ Hypertension}

Besides age, hypertension is consistently reported to be the most common risk factor for cerebral WMH and spinal cord injury [20-22]. The association between hypertension and WMH has been established in cross-sectional [19], and longitudinal studies [20]. Several studies have examined the prevalence of $\mathrm{WMH}$ in hypertensive and high normotensive subjects [23-25]. For instance, the ARIC study [23] reported a $24.6 \%$ prevalence of $\mathrm{WMH}$ among individuals aged 55-72 years, $49 \%$ of whom were hypertensives. Previously increased blood pressure may increase the risk for dementia by inducing small vessel disease and white matter lesions [26]. There is also a suggestion of greater association of hypertension with confluent white matter lesions; van Swieten et al. [27] found diastolic blood pressures were higher in individuals with confluent lesions than in those with no or focal lesions $13 \pm 9$ years earlier.

\section{Large-Vessel Atherosclerosis}

Breteler et al. [25] reported that WMH were related to atherosclerosis, indicated by increased common carotid intima-media thickness and carotid plaques. Similarly, Manolio et al. [28] found that MRI infarcts, ventricular and sulcal widening, and white matter score were strongly associated with carotid intimal-medial thickness and stenosis degree after adjustment for age and sex (all $\mathrm{p}<$ 0.01). Furthermore, de Leeuw et al. [29] showed that the presence of aortic atherosclerosis during midlife, assessed on abdominal radiographs, was significantly associated with the presence of periventricular WMH 20 years later.

Endothelial Dysfunction

Several studies suggest that cerebral leukoaraoisis is associated with impaired endothelial relaxation and reactivity of both cerebral and system vessels. Transcranial
Doppler ultrasound studies have shown significantly impaired vasomotor reactivity in subjects with periventricular white matter lesions [30] and lacunar strokes [31]. A prolonged arteriovenous cerebral transit indicating disordered cerebral microcirculation has been demonstrated in subjects with microangiopathy and vascular dementia [32].

Several authors have drawn upon epidemiologic, pathologic, and experimental studies to suggest that cerebral small vessel endothelial dysfunction, with leakage of plasma components into the vessel wall and surrounding brain tissue leading to neuronal damage, may contribute to the development of lacunar stroke, leukoaraiosis, and dementia [33, 34].

A study by Hassan et al. [35] measuring circulating levels of markers of endothelial activation and damage, intercellular adhesion molecule 1 , thrombomodulin, tissue factor (TF) and tissue factor pathway inhibitor (TFPI) in a prospective series of subjects with lacunar stroke found that the ischemic leukoaraiosis group had a different endothelial marker profile, with lower levels of TFPI $(p=0.01)$ and a higher TF/TFPI ratio $(p=0.01)$ compared with the isolated lacunar infarction group. Thrombomodulin levels were associated with the number of lacunes $(p=0.008)$ and the leukoaraiosis score $(p=0.03)$, but TF levels and the TF/TFPI ratio were associated only with the extent of leukoaraiosis ( $p \leq 0.02$ ). These results suggested that there is evidence of chronic endothelial dysfunction in cerebral small vessel disease and that endothelial prothrombotic changes may be important in mediating the ischemic leukoaraiosis phenotype.

\section{Diabetes}

Some studies have suggested that WMH are associated with diabetes [12, 13]. However, other studies have not confirmed this association [27, 36]. It has been suggested that the reasons for these conflicting results may be differences in sample sizes, grades of $\mathrm{WMH}$, diabetes severity, and diabetes duration across the various study populations [37]. Most recently, a study of nondemented elderly persons has found a significant Pearson correlation with WMH for elevated hemoglobin level, an index of recent (preceding 3 months) glycemic control [38]. Further investigation of any potential relationship between diabetes and WMH is most certainly needed. 


\section{Therapeutic Implications}

Promising Treatment Modalities for Preventing Progression of Ischemic Cerebral White Matter Brain Injury

Antiplatelet Agents

Antiplatelet agents have an established role in reducing secondary stroke and primary cardiac risk [39]. However, up until recently, antiplatelet agents could not be recommended for routine use in the primary prevention of clinically manifest cerebrovascular disease. This was largely due to a lack of high-quality evidence supporting efficacy and the potentially increased risk of hemorrhagic stroke, as noted with prophylactic aspirin use for primary stroke prevention [40]. The results from the Women's Health Study have now suggested that there may be a role for a primary stroke prevention strategy using antiplatelet therapy in selected populations [41]. This study showed a $24 \%$ reduction in ischemic stroke risk (relative risk 0.76 ; 95\% CI $0.63-0.93 ; p=0.009$ ) and a nonsignificant slight increase in the risk of hemorrhagic stroke in favor of aspirin (vs. placebo) among women 45 years of age or older, with no prior history of stroke [41]. The results of the Women's Health Study and the proven efficacy of various antiplatelet agents acting via distinct mechanisms in secondary stroke prevention (please see below) may support the need for developing studies to assess the potential for antiplatelet therapies to mitigate the adverse consequences of $\mathrm{WMH}$ in individuals without clinically manifest cerebrovascular disease.

Aspirin. Aspirin (acetylsalicylic acid) prevents platelet activation by inhibiting the enzyme cyclooxygenase resulting in the blockage of thromboxane generation, and has been shown to be protective in most types of subjects at increased risk of occlusive vascular events [39]. Cyclooxygenase also produces superoxide radicals within vascular endothelial cells. Decreasing superoxide radicals abolishes amyloid-mediated vasoactivity and damage. Thus, aspirin may also reduce endothelial damage through its inhibition of cyclooxygenase [42]. Another mechanism for aspirin's cerebroprotective effects may lie in its known inhibition of matrix metalloproteinase activity [43]. It has been suggested that ongoing cerebral white matter injury is related to matrix metalloproteinase production by microglia/macrophages [44].

Dipyridamole. Dipyridamole is well known to exert antiplatelet activity [45]. Dipyridamole is not only an antiplatelet agent exerting its effects directly on platelets by inhibition of adenosine uptake but it is also an antithrombotic agent utilizing other mechanisms [46]. One of the pharmacological effects of dipyridamole is vasodilatation, which in turn may result in lowering blood pressure [47]. Dipyridamole also directly stimulates the release of endothelial $\mathrm{PGI}_{2}$, as well as reduces the thrombogenicity of subendothelial structures by increasing the productive mediator 13-hydroxyoctadecadienic acid. One study suggested that dipyridamole may act primarily on mediators of inflammation (as determined by C-reactive protein) and endothelial dysfunction (assessed by von Willebrand factor) [48].

Aspirin and Dipyridamole. Preclinical studies have shown a synergistic effect of dipyridamole and acetylsalicylic acid in reducing thrombus formation [49]. The combination of aspirin and dipyridamole is superior to either agent alone in preventing overt recurrent ischemic stroke. The large European Stroke Prevention Study 2 trial found that low-dose aspirin plus dipyridamole more than doubled the reduction in stroke risk achieved with aspirin alone, i.e. a $37 \%$ risk reduction for the combination versus $18.1 \%$ for aspirin alone. The results also suggested that the effects of aspirin and dipyridamole are additive [50].

Clopidogrel. Clopidogrel is an adenosine diphosphate receptor antagonist, which inhibits adenosine diphosphate-induced fibrinogen binding to platelets, a necessary step in the platelet aggregation process. The CAPRIE study revealed a slight advantage for clopidogrel over aspirin in the composite endpoint of ischemic stroke, myocardial infarction or vascular death among a cohort of 19,185 patients with recent ischemic stroke, myocardial infarction or peripheral arterial disease [51, 52].

\section{Antihypertensive Agents}

Subjects taking antihypertensive drugs and who have controlled blood pressure have a reduced risk of severe WMH [20]. Although mean blood pressure is an important predictor of stroke events, the results of recent clinical trials showing benefit of blood pressure reduction even in normotensive individuals [53] indicate that blood pressure likely represents a continuum of risk for stroke, and that the categorical distinction of hypertension from normotension is somewhat artificial [54], thereby implying that the scope of subjects who can be treated with effective stroke-preventive therapies could be widened, and reinforcing the view that the use of antihypertensives should be determined by a person's overall level of risk rather than level of blood pressure alone.

Most salient to this reasoning is the recent report of the French MRI substudy of the PROGRESS clinical trial, which represents the first clinical trial to examine pro- 
gression of white matter abnormalities in subjects treated with add-on antihypertensive therapy. In the PROGRESS trial, hypertensive and high normotensive subjects with a history of stroke received add-on thiazide diuretic and angiotensin-converting enzyme inhibitor (ACEI) therapy (added to their existing blood pressure regimen). A French multicenter group performed an MRI substudy of the PROGRESS trial to determine if active diuretic plus ACEI therapy resulted in a decrease of incidence of new WMH during MRI follow-up, compared to the placebo-treated group of individuals. Dufouil et al. [16] obtained baseline and 3-year follow-up MRI to measure the presence and volume of incidental white matter lesions on 225 persons with prior cerebrovascular disease (stroke or transient ischemic attack). The results demonstrated a statistically significant effect of diuretics plus ACEIs in reducing the occurrence of new white matter lesions, with the treatment effect most pronounced in the subgroup of subjects with advanced leukoaraiosis at the time of study entry.

Of those subjects in the active treatment group who had severe white matter lesions upon entry, none experienced an increase in lesions. The results clearly suggest that an add-on blood-pressure-lowering regimen in subjects with prior stroke stops or delays further covert ischemic brain damage. However, these promising results in subjects who have already suffered an overt clinical stroke need to be extended to subjects with no past history of overt stroke, who may have different rates of progression of covert vascular injury. It is noteworthy that the PROGRESS MRI substudy findings suggest that only subjects with more advanced leukoaraoisis at entry will experience substantial enough progression to benefit from therapy to avert progressive covert vascular brain injury within a few years of intervention.

The general consensus is that blood pressure lowering is the most important factor in the stroke prevention benefit conferred by antihypertensive treatment regardless of the antihypertensive agent class, and that this should be the focus of any management geared at reducing stroke risk. However, there is mounting evidence that certain antihypertensive classes may confer clinical benefit in stroke prevention through additional mechanisms [55].

The Renin-Angiotensin-Aldosterone-Kinin System

Angiotensin II receptor blockers (ARBs) and ACEIs are two classes of antihypertensive drugs that reduce the activity of the renin-angiotensin II system (RAS). Pharmacological modulation of the renin-angiotensin-aldosterone-kinin system is an attractive therapeutic target for the treatment of covert vascular brain injury because abnormalities in the renin-angiotensin-aldosterone-kinin cascade have been implicated in the pathogenesis and clinical expression of brain small vessel disease [56, 57]. ACEIs and ARBs have both been shown beneficial in preventing first and recurrent symptomatic strokes [53, 58, 59]. These agents also appear to lower blood pressure without reducing measures of cerebral perfusion [60].

Genetic association studies in the setting of the Austrian Stroke Prevention Study indicated that polymorphisms in the RAS increase the susceptibility for progression of cerebral small vessel disease. Homozygosity for the T allele of the M235T polymorphism of the angiotensinogen gene was associated with a 3.19-fold increased risk for lesion progression independently of arterial hypertension. These data suggest that drugs influencing the RAS may allow interference of the unfavorable course of cerebral small vessel disease [61].

Angiotensin II (ANG II), the main effector peptide of the RAS, is implicated in the development of vascular pathologies. Considered to be central to the whole vascular continuum, recent investigations have also established a role for ANG II in the recovery of the brain after cerebral insult. ANG II exerts its actions through two receptors: ANG II type 1 (AT1) and type 2 (AT2). Drugs that activate the AT2 receptors, such as ARBs, have consistently been more beneficial for stroke reduction than drugs devoid of such activation, despite an equal fall in arterial pressure $[62,63]$. These clinical and epidemiologic observations are supported by experimental data documenting greater cerebroprotection with ARBs (which increase ANG II levels and stimulate the AT2 receptors) than with ACEIs [62]. Among the many potential effects mediated by stimulation of the AT2 is the neuronal regeneration after injury and inhibition of pathological growth. Indeed, experimental data indicate that ARBs offer double protection in that they inhibit the AT1 receptor-mediated proatherothrombotic effects and enhance the AT2 receptor-mediated protection against ischemia by increasing the generation of ANG II, particularly in small arteries [62]. This latter effect may give ARBs an advantage over ACEIs, because although ACEIs inhibit the AT1-mediated proatherothrombotic effects as well, they also reduce circulating ANG II levels and thereby AT2 receptor-dependent cerebroprotection [62]. However, this potential advantage has not been proven in the clinical arena. The Ongoing Telmisartan Alone and in Combination with Ramipril Global Endpoint Trial (ONTARGET) is an ongoing double-blind randomized study comparing the efficacy and safety of add-on therapy of an 
ARB vs. ACEI in the prevention of cardiovascular events, and will confirm or disconfirm any additional benefits of ARBs over ACEIs [64].

\section{Statins}

The use of statins (HMG-CoA reductase inhibitors) intuitively has potential appeal for preventing WMH injury. Numerous trials have shown that treatment with statins is associated with a significant decrease in the risk of stroke and transient ischemic attack in patients with symptomatic coronary artery disease or multiple risk factors for atherosclerosis [65], and some studies indicate that pretreatment with statins may result in lesser stroke severity [66]. The mechanism by which statins confer vascular protection is likely multifactorial and includes lipoprotein alterations (upregulation of low-density lipoprotein receptor activity and reducing the entry of lowdensity lipoprotein into the circulation), improved endothelial function (upgrade endothelial nitric oxide synthase, inhibit inducible nitric oxide synthase), plaque stabilization, antithrombosis, attenuation of inflammatory cytokine responses, and antioxidant effects [67].

All of this notwithstanding, no study has yet shown that statins are effective in preventing secondary stroke. The SPARCL trial is currently investigating this issue [68]. Pertinent to patients with WMH, the Cardiovascular Health Study examined the association of statin drug use with changes in white matter measures on serial MRI scans separated by 5 years, and found no notable differences in evolution of white matter measures between treatment (statin vs. no statin) groups [69]. However, only limited inferences can be made from these MRI data of the Cardiovascular Health Study subset since the study was observational, the sample size was relatively modest $(n=1,730)$, and the grading system used to measure white matter disease in the study may not have had sufficient sensitivity or interreader reliability to detect significant changes within the study interval. Future larger randomized studies will be needed to explore the role of statins, if any, in reducing ischemic white matter brain injury.

\section{Conclusions}

Although associated with cognitive impairment and dementia, and likely predictors of future vascular events, the varied and covert nature of WMH presents an important obstacle in evaluating the efficacy of therapies. Large sample sizes are likely to be required for treatment trials using clinical endpoints alone, and by the time clinical endpoints become manifest, the burden of brain injury caused by these lesions would be substantial. Clinical endpoints set the ultimate standard for definitive clinical trials, but more sensitive surrogate markers could be useful in evaluating the efficacy of new treatments and selecting the most promising treatments for large trials. An analogy is provided by multiple sclerosis, for which detection of new lesions by contrast-enhanced MRI has been implemented as a surrogate marker of disease activity $[70,71]$, and new lesion detection has been incorporated into guidelines for disease monitoring in therapeutic trials in multiple sclerosis [71]. The European Task Force on Age-Related White Matter Changes has recently concluded that MRI white matter lesions are an appropriate biometric marker for use in phase 2 clinical trials [72]. With the emergence of promising new (and not so new) therapies that may limit cognitive decline in persons with MRI WMH, opportunities may abound for exploring avenues to reduce the immense public burden of cerebral vascular white matter ischemic injury.

\section{References}

1 Broderick J, Miller R, Khoury JC, Alwell K, Kissela MB, Woo D, Shukla R, Moomaw C, Gebel J, Pancioli AM, Brott TG, Kothari RU: Incidence rates of stroke for blacks and whites: preliminary results from the greater Cincinnati/northern Kentucky stroke study. Stroke 2001;32:320.

$\checkmark 2$ Williams G: Incidence and characteristics of total stroke in the united states. BMC Neurol 2001; 1:2
Mittelmark M, Psaty BM, Rautaharju PM, Fried LP, Borhani NO, Tracy RP, Gardin JM, O'Leary DH: Prevalence of cardiovascular diseases among older adults. The cardiovascular health study. Am J Epidemiol 1993;137:311317.

4 Awad I, Johnson PC, Spetzler RF, Hodak JA: Incidental subcortical lesions identified on magnetic resonance imaging in the elderly. Postmortem pathological findings. Stroke 1986;17:1090-1097.
Kertesz A, Black SE, Tokar G, Benke T, Carr T, Nicholson L: Periventricular and subcortical hyperintensities on magnetic resonance imaging. 'Rims, caps, and unidentified bright objects'. Arch Neurol 1988;45:404-408.

6 Kidwell C, Saver JL: Causes and consequences of leukoaraiosis: a review. Facts Res Gerontol 1996(suppl stroke):115-135.

7 de Groot J, de Leeuw FE, Oudkerk M, Hofman A, Jolles J, Breteler MM: Cerebral white matter lesions and depressive symptoms in elderly adults. Arch Gen Psychiatry 2000;57:10711076. 
$>8$ Baloh R, Yue Q, Socotch TM, Jacobson KM: White matter lesions and disequilibrium in older people. 1. Case-control comparison. Arch Neurol 1995;52:970-974.

-9 Price T, Manolio TA, Kronmal RA, Kittner SJ, Yue NC, Robbins J, Anton-Culver H, O'Leary D: Silent brain infarction on magnetic resonance imaging and neurological abnormalities in community-dwelling older adults. The Cardiovascular Health Study. CHS Collaborative Research Group. Stroke 1997;28:1158-1164.

10 Longstreth W: Brain abnormalities in the elderly: frequency and predictors in the United States (the Cardiovascular Health Study). Cardiovascular Health Study Collaborative Research Group. J Neural Transm Suppl 1998; 53:9-16.

11 Hachinski V, Potter P, Merskey H: Leukoaraiosis: an ancient term for a new problem. Can J Neurol Sci 1986;13:533-534.

-12 Schmidt R, Fazekas F, Kleinert G, Offenbacher H, Gindl K, Payer F, Freidl W, Niederkorn K, Lechner H: Magnetic resonance imaging signal hyperintensities in the deep and subcortical white matter. A comparative study between stroke patients and normal volunteers. Arch Neurol 1992;49:825-827.

-13 Fazekas F, Niederkorn K, Schmidt R, Offenbacher $\mathrm{H}$, Horner S, Bertha $\mathrm{G}$, Lechner $\mathrm{H}$ : White matter signal abnormalities in normal individuals: correlation with carotid ultrasonography, cerebral blood flow measurements, and cerebrovascular risk factors. Stroke 1988; 19:1285-1288.

14 Schmidt R, Schmidt H, Kapeller P, Enzinger C, Ropele S, Saurugg R, Fazekas F: The natural course of MRI white matter hyperintensities. J Neurol Sci 2002;203-204:253-257.

15 Schmidt R, Enzinger C, Ropele S, Schmidt H, Fazekas F: Progression of cerebral white matter lesions: 6-year results of the Austrian stroke prevention study. Lancet 2003;361:20462048.

16 Dufouil C, Chalmers J, Coskun O, Besancon $\mathrm{V}$, Bousser MG, Guillon P, MacMahon S, Mazoyer B, Neal B, Woodward M, TzourioMazoyer N, Tzourio C: Effects of blood pressure lowering on cerebral white matter hyperintensities in patients with stroke: the PROGRESS (Perindopril Protection Against Recurrent Stroke Study) Magnetic Resonance Imaging Substudy. Circulation 2005; 112 1644-1650.

17 Fazekas F, Kleinert R, Offenbacher H, Schmidt R, Kleinert G, Payer F, Radner H, Lechner H: Pathologic correlates of incidental MRI white matter signal hyperintensities. Neurology 1993;43:1683-1689.

-18 Liao D, Cooper L, Cai J, Toole J, Bryan N, Burke G, Shahar E, Nieto J, Mosley T, Heiss $\mathrm{G}$ : The prevalence and severity of white matter lesions, their relationship with age, ethnicity, gender, and cardiovascular disease risk factors: the ARIC study. Neuroepidemiology 1997;16: 149-162.
19 Pantoni L, Garcia JH: The significance of cerebral white matter abnormalities 100 years after Binswanger's report. A review. Stroke 1995;26:1293-1301.

20 Dufouil C, de Kersaint-Gilly A, Besancon V, Levy C, Auffray E, Brunnereau L, Alperovitch A, Tzourio C: Longitudinal study of blood pressure and white matter hyperintensities: the EVA-MRI cohort. Neurology 2001;56:921926.

21 Lee S, Park SJ, Ki HK, Gwon HC, Chung CS, Byun HS, Shin KJ, Shin MH, Lee WR: Prevalence and risk factors of silent cerebral infarction in apparently normal adults. Hypertension 2000;36:73-77.

22 Longstreth WT Jr, Bernick C, Manolio TA, Bryan N, Jungreis CA, Price TR: Lacunar infarcts defined by magnetic resonance imaging of 3,660 elderly people: the cardiovascular health study. Arch Neurol 1998;55:12171225 .

23 Liao D, Cooper L, Cai J, Toole JF, Bryan NR, Hutchinson RG, Tyroler HA: Presence and severity of cerebral white matter lesions and hypertension, its treatment, and its control. The ARIC study. Atherosclerosis Risk in Communities Study. Stroke 1996;27:2262-2270.

24 Longstreth W, Manolio TA, Arnold A, Burke GL, Bryan N, Jungreis CA, Enright PL, O'Leary D, Fried L: Clinical correlates of white matter findings on cranial magnetic resonance imaging of 3,301 elderly people. The Cardiovascular Health Study. Stroke 1996;27:12741282.

25 Breteler MM, van Swieten JC, Bots ML, Grobbee DE, Claus JJ, van den Hout JH, van Harskamp F, Tanghe HL, de Jong PT, van Gijn J, et al: Cerebral white matter lesions, vascular risk factors, and cognitive function in a population-based study: the Rotterdam study. Neurology 1994;44:1246-1252.

-26 Skoog I, Lernfelt B, Landahl S, Palmertz B, Andreasson LA, Nilsson L, Persson G, Oden A, Svanborg A: 15-year longitudinal study of blood pressure and dementia. Lancet 1996; 347:1141-1145.

27 van Swieten J, Geyskes GG, Derix MM, Peeck BM, Ramos LM, van Latum JC, van Gijn J: Hypertension in the elderly is associated with white matter lesions and cognitive decline. Ann Neurol 1991;30:825-830.

28 Manolio T, Burke GL, O’Leary DH, Evans G, Beauchamp N, Knepper L, Ward B: Relationships of cerebral MRI findings to ultrasonographic carotid atherosclerosis in older adults: the Cardiovascular Health Study. CHS Collaborative Research Group. Arterioscler Thromb Vasc Biol 1999; 19:356-365.

29 de Leeuw FE, De Groot JC, Oudkerk M, Witteman JC, Hofman A, van Gijn J, Breteler MM: Aortic atherosclerosis at middle age predicts cerebral white matter lesions in the elderly. Stroke 2000;31:425-429.

30 Bakker S, de Leeuw FE, de Groot JC, Hofman A, Koudstaal PJ, Breteler MM: Cerebral vasomotor reactivity and cerebral white matter lesions in the elderly. Neurology 1999;52:578583.
31 Molina C, Sabin JA, Montaner J, Rovira A, Abilleira S, Codina A: Impaired cerebrovascular reactivity as a risk marker for first-ever lacunar infarction: a case-control study. Stroke 1999;30:2296-2301.

32 Puls I, Hauck K, Demuth K, Horowski A, Schliesser M, Dorfler P, Scheel P, Toyka KV, Reiners K, Schoning M, Becker G: Diagnostic impact of cerebral transit time in the identification of microangiopathy in dementia: a transcranial ultrasound study. Stroke 1999;30: 2291-2295.

33 Wardlaw J, Sandercock PA, Dennis MS, Starr $\mathrm{J}$ : Is breakdown of the blood-brain barrier responsible for lacunar stroke, leukoaraiosis, and dementia? Stroke 2003;34:806-812.

34 Baloh R, Vinters HV: White matter lesions and disequilibrium in older people. 2. Clinicopathologic correlation. Arch Neurol 1995;52:975981.

-35 Hassan A, Hunt BJ, O’Sullivan M, Parmar K, Bamford JM, Briley D, Brown MM, Thomas DJ, Markus HS: Markers of endothelial dysfunction in lacunar infarction and ischaemic leukoaraiosis. Brain 2003; 126:424-432.

-36 Bogousslavsky J, Regli F, Uske A: Leukoencephalopathy in patients with ischemic stroke. Stroke 1987; 18:896-899.

37 Fukuda H, Kitani M: Differences between treated and untreated hypertensive subjects in the extent of periventricular hyperintensities observed on brain MRI. Stroke 1995;26:15931597.

38 Murray A, Staff RT, Shenkin SD, Deary IJ, Starr JM, Whalley LJ: Brain white matter hyperintensities: relative importance of vascular risk factors in nondemented elderly people. Radiology 2005;237:251-257.

39 Collaborative meta-analysis of randomised trials of antiplatelet therapy for prevention of death, myocardial infarction, and stroke in high risk patients. BMJ 2002;324:71-86.

40 Rodondi N, Bauer DC: Assessing the risk/benefit profile before recommending aspirin for the primary prevention of cardiovascular events. Am J Med 2004; 117:528-530.

41 Ridker P, Cook NR, Lee IM, Gordon D, Gaziano JM, Manson JE, Hennekens CH, Buring $\mathrm{JE}$ : A randomized trial of low-dose aspirin in the primary prevention of cardiovascular disease in women. N Engl J Med 2005;352:12931304.

42 Broe GA, Grayson DA, Creasey HM, Waite LM, Casey BJ, Bennett HP, Brooks WS, Halliday GM: Anti-inflammatory drugs protect against Alzheimer disease at low doses. Arch Neurol 2000;57:1586-1591.

43 Jiang MC, Liao CF, Lee PH: Aspirin inhibits matrix metalloproteinase-2 activity, increases E-cadherin production, and inhibits in vitro invasion of tumor cells. Biochem Biophys Res Commun 2001;282:671-677.

44 Rosenberg GA, Sullivan N, Esiri MM: White matter damage is associated with matrix metalloproteinases in vascular dementia. Stroke 2001;32:1162-1168. 
45 Emmons PR, Harrison MJ, Honour AJ, Mitchell JR: Effect of dipyridamole on human platelet behaviour. Lancet 1965;ii:603-606.

46 Eisert WG: Near-field amplification of antithrombotic effects of dipyridamole through vessel wall cells. Neurology 2001;57:S20-S23.

-47 Aktas B, Utz A, Hoenig-Liedl P, Walter U, Geiger J: Dipyridamole enhances NO/cGMPmediated vasodilator-stimulated phosphoprotein phosphorylation and signaling in human platelets: in vitro and in vivo/ex vivo studies. Stroke 2003;34:764-769.

48 Zhao L, Leonardi-Bee J, Weaver C, Heptinstall S, Bath P: Effect of aspirin, clopidogrel and dipyridamole on soluble markers of vascular stress in patients with prior stroke. 13th Eur Stroke Conf, Mannheim-Heidelberg, May 2004.

-49 Honour AJ, Hockaday TD, Mann JI: The synergistic effect of aspirin and dipyridamole upon platelet thrombi in living blood vessels. Br J Exp Pathol 1977;58:268-272.

- 50 Diener HC, Cunha L, Forbes C, Sivenius J, Smets P, Lowenthal A: European stroke prevention study. 2. Dipyridamole and acetylsalicylic acid in the secondary prevention of stroke. J Neurol Sci 1996;143:1-13.

-51 Ringleb PA, Bhatt DL, Hirsch AT, Topol EJ, Hacke W: Benefit of clopidogrel over aspirin is amplified in patients with a history of ischemic events. Stroke 2004;35:528-532.

-52 Hirsh J, Bhatt DL: Comparative benefits of clopidogrel and aspirin in high-risk patient populations: lessons from the CAPRIE and CURE studies. Arch Intern Med 2004; 164: 2106-2110.

-53 Randomised trial of a perindopril-based bloodpressure-lowering regimen among 6,105 individuals with previous stroke or transient ischaemic attack. Lancet 2001;358:1033-1041.

-54 Gorelick PB: New horizons for stroke prevention: PROGRESS and HOPE. Lancet Neurol 2002;1:149-156.

55 Ruland S, Gorelick PB: Are cholesterol-lowering medications and antihypertensive agents preventing stroke in ways other than by controlling the risk factor? Curr Neurol Neurosci Rep 2003;3:21-26.
56 Takami S, Imai Y, Katsuya T, Ohkubo T, Tsuji I, Nagai K, Satoh H, Hisamichi S, Higaki J, Ogihara T: Gene polymorphism of the reninangiotensin system associates with risk for lacunar infarction. The Ohasama study. Am J Hypertens 2000;13:121-127.

57 Hassan A, Lansbury A, Catto AJ, Guthrie A, Spencer J, Craven C, Grant PJ, Bamford JM: Angiotensin converting enzyme insertion/deletion genotype is associated with leukoaraiosis in lacunar syndromes. J Neurol Neurosurg Psychiatry 2002;72:343-346.

58 Dahlof B, Devereux RB, Kjeldsen SE, Julius S, Beevers G, Faire U, Fyhrquist F, Ibsen H, Kristiansson K, Lederballe-Pedersen O, Lindholm LH, Nieminen MS, Omvik P, Oparil S, Wedel $\mathrm{H}$ : Cardiovascular morbidity and mortality in the Losartan Intervention For Endpoint reduction in hypertension study (LIFE): a randomised trial against atenolol. Lancet 2002; 359:995-1003

-59 Yusuf S, Sleight P, Pogue J, Bosch J, Davies R, Dagenais G: Effects of an angiotensin-converting-enzyme inhibitor, ramipril, on cardiovascular events in high-risk patients. The Heart Outcomes Prevention Evaluation Study Investigators. N Engl J Med 2000;342:145-153; errata in N Engl J Med 2000;342:748 and N Engl J Med 2000;342:1376.

60 Bath P: High blood pressure as risk factor and prognostic predictor in acute ischaemic stroke: when and how to treat it? Cerebrovasc Dis 2004;17(suppl 1):51-57.

61 Schmidt R, Fazekas F, Enzinger C, Ropele S, Kapeller P, Schmidt H: Risk factors and progression of small vessel disease-related cerebral abnormalities. J Neural Transm Suppl 2002: 47-52.

62 Fournier A, Messerli FH, Achard JM, Fernandez L: Cerebroprotection mediated by angiotensin II: a hypothesis supported by recent randomized clinical trials. J Am Coll Cardiol 2004;43:1343-1347.
63 Schrader J, Luders S, Kulschewski A, Hammersen F, Plate K, Berger J, Zidek W, Dominiak P, Diener HC: Morbidity and mortality after stroke, eprosartan compared with nitrendipine for secondary prevention: principal results of a prospective randomized controlled study (MOSES). Stroke 2005;36:1218-1226.

$64 \mathrm{http}: / /$ www.ontarget-micardis.com/studyprog/ ontar/ontarget.htm). Last accessed November $16,2005$.

65 Ovbiagele B, Kidwell, CS, Saver JL: Expanding indications for statins in cerebral ischemia: a quantitative study. Arch Neurol 2005;62: $67-72$.

66 Greisenegger S, Mullner M, Tentschert S, Lang W, Lalouschek W: Effect of pretreatment with statins on the severity of acute ischemic cerebrovascular events. J Neurol Sci 2004;221:510.

67 Davignon J, Laaksonen R: Low-density lipoprotein-independent effects of statins. Curr Opin Lipidol 1999;10:543-559.

- 68 Amarenco P, Bogousslavsky J, Callahan AS, Goldstein L, Hennerici M, Sillsen H, Welch MA, Zivin J: Design and baseline characteristics of the stroke prevention by aggressive reduction in cholesterol levels (SPARCL) study. Cerebrovasc Dis 2003;16:389-395.

69 Bernick C, Katz R, Smith NL, Rapp S, Bhadelia R, Carlson M, Kuller L: Statins and cognitive function in the elderly: the cardiovascular health study. Neurology 2005;65:1388-1394.

70 Miller D, Barkhof F, Nauta JJ: Gadolinium enhancement increases the sensitivity of MRI in detecting disease activity in multiple sclerosis. Brain 1993;116:1077-1094.

71 Miller D, Albert PS, Barkhof F, Francis G, Frank JA, Hodgkinson S, Lublin FD, Paty DW, Reingold SC, Simon J: Guidelines for the use of magnetic resonance techniques in monitoring the treatment of multiple sclerosis. US National MS Society Task Force. Ann Neurol 1996;39:6-16.

72 Schmidt R, Scheltens P, Erkinjuntti T, Pantoni L, Markus HS, Wallin A, Barkhof F, Fazekas F: White matter lesion progression: a surrogate endpoint for trials in cerebral small-vessel disease. Neurology 2004;63:139144. 